\title{
Dual-pump Optical Parametric Oscillation in a 4H-SiC-on-insulator Microring Resonator
}

Shi, Xiaodong; Fan, Weichen; Yi, Ailun; Ou, Xin; Rottwitt, Karsten; Ou, Haiyan

Link to article, DOI:

10.1109/CLEO/Europe-EQEC52157.2021.9542432

Publication date:

2021

Document Version

Peer reviewed version

Link back to DTU Orbit

Citation (APA):

Shi, X., Fan, W., Yi, A., Ou, X., Rottwitt, K., \& Ou, H. (2021). Dual-pump Optical Parametric Oscillation in a 4HSiC-on-insulator Microring Resonator. Abstract from 2021 Conference on Lasers and Electro-Optics Europe and European Quantum Electronics Conference, Munich, Bavaria, Germany. https://doi.org/10.1109/CLEO/EuropeEQEC52157.2021.9542432

\section{General rights}

Copyright and moral rights for the publications made accessible in the public portal are retained by the authors and/or other copyright owners and it is a condition of accessing publications that users recognise and abide by the legal requirements associated with these rights.

- Users may download and print one copy of any publication from the public portal for the purpose of private study or research.

- You may not further distribute the material or use it for any profit-making activity or commercial gain

- You may freely distribute the URL identifying the publication in the public portal 


\title{
Dual-pump Optical Parametric Oscillation in a 4H-SiC-on-insulator Microring Resonator
}

\author{
Xiaodong Shi ${ }^{1}$, Weichen Fan $^{1}$, Ailun $\mathrm{Yi}^{2}$, Xin $\mathrm{Ou}^{2}$, Karsten Rottwitt ${ }^{1}$, Haiyan $\mathrm{Ou}^{1, *}$ \\ 1. DTU Fotonik, Technical University of Denmark, Building 343, DK-2800 Lyngby, Denmark \\ 2. State Key Laboratory of Functional Materials for Informatics, Shanghai Institute of Microsystem and Information Technology, Chinese \\ Academy of Sciences, Shanghai 200050, China \\ * Corresponding author: haou@fotonik.dtu.dk
}

Silicon carbide ( $\mathrm{SiC}$ ) has large refractive index, wide bandgap, and strong material-based second- and thirdorder nonlinearities. Thus, in recent years, $\mathrm{SiC}$ has attracted considerable interests in quantum and nonlinear integrated photonics [1-3] with potential applications within broadband nonlinear light sources, including photonpair sources, supercontinuum generation, and frequency combs. Optical parametric oscillation (OPO) is regarded as a promising way to produce new frequencies and an important tool in generation of coherent light sources, such as frequency combs. In this work, we experimentally demonstrate a Kerr-nonlinearity based dual continuouswave $(\mathrm{CW})$ pumped $\mathrm{OPO}$ in a $4 \mathrm{H}-\mathrm{SiC}-$ on-insulator $(4 \mathrm{H}-\mathrm{SiCOI})$ microring resonator.

The $4 \mathrm{H}-\mathrm{SiCOI}$ chip is fabricated by the Smart-cut process [4]. The microring resonator is defined by electronbeam lithography with the positive resist AR-P 6200, coated on the 4H-SiCOI chip. After the electron-beam evaporation of aluminum and the lift-off process, the exposed pattern is transferred to the aluminum layer, which is used as the hard mask to etch $\mathrm{SiC}$. The $\mathrm{SiC}$ is dry etched with $\mathrm{SF}_{6}$. After stripping the metal mask, the waveguides are top cladded with $\mathrm{SiO}_{2}$. The microring resonator, shown in Fig. 1(a), has a radius of $33 \mu \mathrm{m}$ and a cross-sectional dimension of $W \times H=1200 \mathrm{~nm} \times 400 \mathrm{~nm}$. Linear characterization of the fundamental TE mode resonance at $1567.2 \mathrm{~nm}$ is plotted in Fig. 1(b). Fitted by the Lorentzian lineshape, the full-width at half-maximum (FWHM) of $34 \mathrm{pm}$ can be extracted. The corresponding quality factor of the microring resonator and the linear propagation loss are subsequently calculated to be $\sim 46000$ and $\sim 8 \mathrm{~dB} / \mathrm{cm}$, respectively.

In the experiment, we launched two TE polarized $\mathrm{CW}$ pumps with one free-spectral-range separation $(F S R \approx$ $0.5 \mathrm{THz}$ ) into the waveguide. One pump was at $1564.01 \mathrm{~nm}$, with an on-chip power of $50.1 \mathrm{~mW}$, which was amplified by the erbium-doped fiber amplifier (EDFA). The other pump, swept from $1566.94 \mathrm{~nm}$ to $1567.94 \mathrm{~nm}$, was amplified to $79.4 \mathrm{~mW}$. High incident power induces resonance shift. Through sweeping, the two pumps are able to be kept on resonances simultaneously and stably, without any active temperature controlling. The OPO is observed from the transmission spectrum. As can be seen in Fig. 1(c), four new frequencies are generated by cascaded four-wave mixing. The OPO usually has a symmetric spectrum, so it is fair to predict there should be two more new frequency lines in the short wavelength range, which are buried in the amplified spontaneous emission noise from the EDFA.

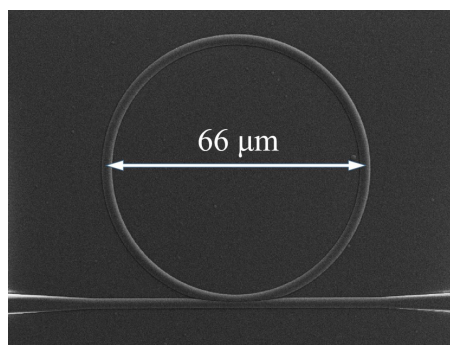

(a)

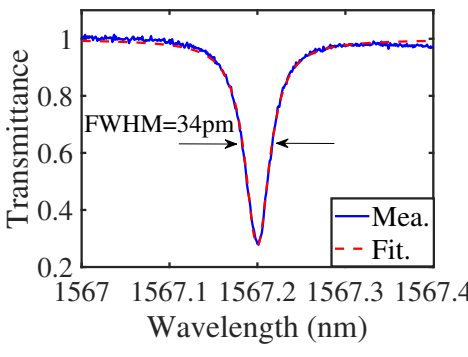

(b)

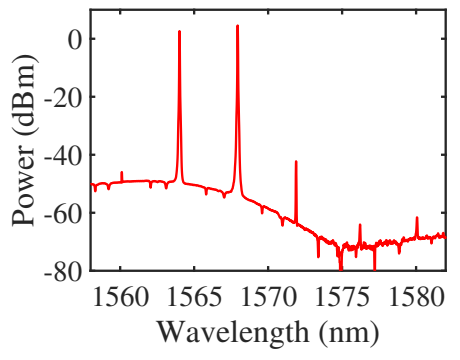

(c)

Fig. 1 (a) Scanning electron microscope image of the $\mathrm{SiC}$ microring resonator. (b) Measured spectrum (blue solid line) and fitting curve (red dash line) of the fundamental TE mode resonance at $1567.2 \mathrm{~nm}$. (c) OPO spectrum generated from the SiC microring resonator with two CW pumps on resonances. The adjacent frequency lines have an interval of one FSR.

It is expected that the OPO can be further enhanced and potentially excite frequency combs, by improving the $4 \mathrm{H}-\mathrm{SiCOI}$ chip and $\mathrm{SiC}$ waveguide fabrication processes, in order to reduce the material absorption loss and the waveguide surface scattering loss, respectively.

\section{Acknowledgement}

This work is supported by European Union's Horizon 2020 FET Open (SiComb, No.899679).

\section{References}

[1] D. M. Lukin, et al., "4H-silicon-carbide-on-insulator for Integrated Quantum and Nonlinear Photonics," Nat. Photonics 14, 330-334 (2020).

[2] D. M. Lukin, et al., "Integrated Quantum Photonics with Silicon Carbide: Challenges and Prospects," PRX Quantum 1, 020102 (2020).

[3] M. A. Guidry, et al., "Optical Parametric Oscillation in Silicon Carbide Nanophotonics," Optica 7, 1139-1142 (2020).

[4] A. Yi, et al., "Wafer-scale 4H-silicon carbide-on-insulator (4H-SiCOI) Platform for Nonlinear Integrated Optical Devices," Opt. Mater., $109990(2020)$ 